\title{
UV-light photocatalytic degradation of non-ionic surfactants using ZnO nanoparticles
}

\author{
K. Huszla ${ }^{1}$ (D) M. Wysokowski ${ }^{2} \cdot$ A. Zgoła-Grześkowiak ${ }^{1} \cdot$ M. Staszak ${ }^{2} \cdot$ M. Janczarek ${ }^{2} \cdot$ T. Jesionowski $^{2} \cdot$ B. Wyrwas $^{1}$
}

Received: 21 August 2020 / Revised: 14 December 2020 / Accepted: 18 January 2021 / Published online: 8 February 2021

(c) The Author(s) 2021

\begin{abstract}
The aim of this study was to evaluate the performance of zinc oxide nanoparticles as a photocatalyst for photodegradation of two model non-ionic surfactants (Triton X-100 and $\mathrm{C}_{12} \mathrm{E}_{10}$ ). The first part of the investigation was focused on the synthesis and characterization of $\mathrm{ZnO}$ nanoparticles, since its crystalline structure strongly impacts its photocatalytic properties. Based on the results of the XRD analysis, it was concluded that the obtained material occurred in the form of hexagonal wurtzite with a polycrystalline structure. FT-IR and XPS analyses were used to elucidate and confirm the nanomaterial structure, whereas investigation of $\mathrm{N}_{2}$ adsorption/desorption and SEM/TEM imaging allowed to establish that the synthesized $\mathrm{ZnO}$ was characterized as a mesoporous material with uniform, spherical shape and particle size fluctuating between 90 and 130 $\mathrm{nm}$. The second part of the study included spectrophotometric assessment of the photodegradation process. The use of the obtained $\mathrm{ZnO}$ nanoparticles allowed to achieve efficient photodegradation of both $\mathrm{C}_{12} \mathrm{E}_{10}(92 \%)$ and Triton X-100 (82\%) after $1 \mathrm{~h}$ of UV irradiation. The Langmuir-Hinshelwood mechanism was used to describe the reaction kinetics. Subsequent LC-MS/MS analysis of the residues indicated that the degradation mechanism is most likely based on both central fission of the surfactant molecules with further terminal oxidation of poly(ethylene glycol) and terminal oxidation leading to carboxylic derivatives of surfactants.
\end{abstract}

Keywords Photodegradation $\cdot$ Nanomaterials $\cdot$ Zinc oxide $\cdot$ Surfactants $\cdot \mathrm{C}_{12} \mathrm{E}_{10} \cdot$ Triton X-100 $\cdot$ Central fission

\section{Introduction}

Surface active agents (surfactants) are among the most commonly used products in the chemical industry and possess a broad spectrum of practical applications (Rosen and Kunjappu 2012). The versatility of surfactants results from their specific structure and properties, which allow for emulsification, micellization, wetting and reduction of surface tension (Rosen and Kunjappu 2012). Surfactants are usually classified based on the nature of their hydrophilic group as:

Editorial responsibility by Senthil Kumar Ponnusamy.

K. Huszla

klaudia.m.huszla@doctorate.put.poznan.pl

1 Institute of Chemistry and Technical Electrochemistry, Faculty of Chemical Technology, Poznan University of Technology, 60965 Poznan, Poland

2 Institute of Chemical Technology and Engineering, Faculty of Chemical Technology, Poznan University of Technology, 60965 Poznan, Poland anionic, cationic, zwitterionic and non-ionic (Rosen and Kunjappu 2012). Analysis of global production in terms of surfactant structure indicates that the industrial synthesis is dominated by anionic and non-ionic surfactants. Surfactants are present in such diverse products as motor oils, pharmaceuticals, detergents, drilling muds used in prospecting for petroleum, and flotation agents used in mineral processing (Rosen and Kunjappu 2012; Pattanaik and Venugopal 2019). The last decades have shown the practical utility of surfactants in more sophisticated technologies including synthesis of nanomaterials (Deng et al. 2018), production of advanced electronic devices (Deng et al. 2018; Li et al. 2018; Kim et al. 2018), biotechnology (Janoska et al. 2018), cell imaging (Komatsu et al. 2018) and many others. Future outlook for the global surfactants market forecasts that the market will grow to 16.60 million tons by 2022 . The growing spectrum of surfactant applications also results in an increased quantity of surfactants released to the terrestrial and aquatic environments (Liwarska-Bizukojc et al. 2005). Uncontrolled releases of industrial wastewater with high concentration of surfactants are particularly hazardous, 
especially in developing countries (Babayemi et al. 2017; Huszla et al. 2018). It has been reported that surfactants and the products of their biodegradation are harmful for a variety of organisms (Giger et al. 1984; Könnecker et al. 2011; Lechugaet al. 2016; Rios et al. 2018; Shukla and Trivedi 2018), including humans (Cserati et al. 2002; Khunt et al. 1993) reported that surfactants alter soil chemistry and soil biology even at low concentrations and, as a result, significantly suppress the development of plant roots. Very recently, it has been reported that detergents present in irrigation water affect maize (Zea mays L.) at higher concentrations by impairing its light-harvesting pigments and cell viability (Uzma et al. 2018). Several studies regarding the aquatic toxicity of surfactants indicate that these compounds induce oxidative stress and tend to bioaccumulate in fish (Shukla and Trivedi 2018), which act as an exposure gateway to the human consumers (Tan et al. 2010).

The environmental risk caused by surfactants mostly depends on the final concentration reached in the aquatic medium, but it also varies based on their chemical structure. Nevertheless, successful elimination of surfactant contamination from wastewater is of critical importance (Jardak et al. 2016). Various physical, chemical and biological methods of surfactant detoxification are reported (Noorimotlagh 2019, Rebello et al. 2014). Biodegradation is one of the cheapest and most commonly applied methods for neutralization of surfactant-polluted wastewater. Nevertheless, uncontrolled biodegradation may lead to the formation of stable degradation products, which are even more harmful than the initial surfactants (Giger et al. 1984). Additionally, high surfactant load may result in incomplete biodegradation and cause the wastewater treatment plants to discharge considerable amounts of surfactant degradation products into the environment (Chen et al. 2005, Wyrwas et al. 2013). Therefore, the search for alternative, highly effective methods for neutralization of surfactants is still of high importance. Heterogenous photocatalysis is one of the promising modern methods of eliminating hazardous organic pollutants, which received great attention (Byrne et al. 2015; Fox and Dulay 1993; Kabra et al. 2004; Noorimotlagh et al. 2019). In photocatalysis, semiconductors are irradiated by UV or near-UV light. When the photon energy $(h \nu)$ is equal to or exceeds the band gap of the semiconductor/photocatalyst, a photon is absorbed and this excites an electron from the valance band to the conduction band, simultaneously leaving positive charge holes in the valance band. The electron and hole pairs then migrate to the surface of the applied photocatalyst and participate in a series of redox reactions forming reactive oxygen species (Fox and Dulay 1993; Imbhadon and Fitzpatrick et al. 2013; Kabra et al. 2004). Thus, due to the strong oxidizing ability, photocatalysis is an efficient method to decompose organic contaminants in water, especially in heavy contaminated industrial waste waters, which are not suitable for biological processing due to their toxicity to microorganisms (Imbhadon and Fitzpatrick et al. 2013). Photocatalytic degradation of various organic pollutants including dyes (Sałata et al. 2019, Siwińska-Ciesielczyk et al. 2020), phenol (Shet and Shetty 2015, Norman et al. 2018), antibiotics and pharmaceuticals (Liu et al. 2018; Sabouni and Gomaa 2019; Jia et al. 2020 ) with the use of broad variety of photocatalysts is comprehensively studied and well described. However, there is a considerable lack of reports regarding photocatalytic degradation of surfactants. Taking into account the recent progress in the design and modification of photocatalysts, it is surprising that photocatalytic degradation of surfactants was realized mostly by utilization of commercial $\mathrm{TiO}_{2}$ as a photocatalyst (Hidaka and Zhao et al. 1992; Hidaka et al. 1986; 1989; 1992a, b; Rao and Dube 1995; Zhao et al. 1993). Only recently, Noorimotlagh et al. (2019) reported the application of $\mathrm{TiO}_{2}$ modified with graphite for the treatment of surfactants and Rahimpour et al. (2020) reported application of $\mathrm{ZnO} / \mathrm{FeVO}_{4}$ in photoFenton-like process in SDS removal. Nevertheless, there is still a broad field for research regarding the photodegradation of surfactants with modern sensitized photocatalysts or alternatives to $\mathrm{TiO}_{2}$. In the framework of this study, for the first time, we report the application of $\mathrm{ZnO}$ nanoparticles as an effective catalyst for the photocatalytic degradation of non-ionic surfactants. The aim of this study was to evaluate the performance of zinc oxide nanoparticles as a photocatalyst for photodegradation of two model non-ionic surfactants (Triton X-100 and $\mathrm{C}_{12} \mathrm{E}_{10}$ ).

\section{Materials and methods}

\section{Reagents and chemicals}

The non-ionic surfactants dodecyl alcohol ethoxylate $\left(\mathrm{C}_{12} \mathrm{E}_{10}\right)$ and octylphenol ethoxylate (Triton X-100) were obtained from Sigma-Aldrich (Saint Louis, MO, USA). All reagents used in spectrophotometric analysis (bismuth(III) nitrate, glacial acetic acid, potassium iodide, barium chloride, anhydrous sodium phosphate, thiourea, nitric acid) were obtained from Avantor Performance Materials Poland S.A. (Gliwice, Poland). Zinc acetate dihydrate used in synthesis of $\mathrm{ZnO}$ nanoparticles was obtained from SigmaAldrich (Saint Louis, MO, USA). LC/MS-grade methanol and ammonium acetate were purchased from Sigma-Aldrich (Saint Louis, MO, USA). HPLC-grade water was prepared by reverse osmosis in a Demiwa system from Watek (Ledec and Sazavou, The Czech Republic) followed by double distillation from a quartz apparatus. 


\section{Synthesis of $\mathrm{ZnO}$ nanoparticles}

The preparation of $\mathrm{ZnO}$ was performed according to the method published previously by Tian et al. (2012) with a slight modification. The crucible containing $25 \mathrm{~g}$ of solid zinc acetate dihydrate was placed in the furnace P320 MB1 (Nabertherm GmBH, Germany) and annealed to $600^{\circ} \mathrm{C}$ with a heating rate of $5^{\circ} \mathrm{C} / \mathrm{min}$ in the air atmosphere and kept at the maximum temperature for $120 \mathrm{~min}$. Afterward, the sample was naturally cooled down to ambient temperature and $9 \mathrm{~g}$ of the gray precipitate was collected and used for further studies.

\section{Physicochemical characterization of $\mathrm{ZnO}$ nanoparticles}

The XRD analysis was performed with a D8 Advance diffractometer (Bruker, Germany) equipped with an X-ray tube with $\mathrm{Cu} \mathrm{K} \alpha$ radiation $(\alpha=1.5418 \AA$ ). The patterns were obtained in a step-scanning mode $\left(\Delta 2 \theta=0.05^{\circ}\right)$ over an angular range of $10-80^{\circ}$. The average crystallite size has been calculated with the Scherrer equation (1) by using the full width at half maximum (FWHM) values of the (101) peak line.

$D=K \lambda /(\beta \cos \Theta)$

where $\mathrm{D}$ is the mean crystallite size, $\mathrm{K}$ is the Scherrer constant, $\beta$ is the full width at half maximum (FWHM) of the diffraction line, $\Theta$ is the diffraction angle, and $\lambda$ is the wavelength of the $\mathrm{X}$-ray radiation.

The FT-IR spectra were recorded using a VERTEX 70 Fourier transform infrared spectrophotometer (BrukerOptik $\mathrm{GmbH}$, Germany). The spectrometer was equipped with a multireflection variable angle horizontal ATR accessory (Platinum ATR - BrukerOptik GmbH, Germany). Data processing was carried out with the Opus 7.5 software package (BrukerOptik GmbH, Germany). The X-ray photoelectron spectroscopy (XPS) experiments were recorded on Specs UHV spectrometer (SPECS, Germany) with a charge neutralizer. The $\mathrm{C} 1 \mathrm{~s}$ peak at $284.8 \mathrm{eV}$ was used as a reference to rectify the binding energies. The microstructure of the obtained photocatalyst was visualized using an EVO40 scanning electron microscope. Before testing, samples were coated with gold for $45 \mathrm{~s}$ using a Balzers PV205 P sputter (Zeiss, Germany). Additionally, to get a better insight into the nanostructural features, the obtained material was analyzed using a Jeol 1200 EX II transmission electron microscope (TEM, Jeol, Peabody, MA, USA) at an accelerating voltage of $100 \mathrm{kV}$. The textural properties of the synthesized $\mathrm{ZnO}$ nanoparticles were determined by $\mathrm{N}_{2}$ adsorption/desorption isotherm measurements at $-196^{\circ} \mathrm{C}$ using an ASAP
2020 physisorption analyzer (Micromeritics Instrument Co., Norcross, CA, USA). The Brunauer-Emmett-Teller (BET) model was used to calculate the specific surface area of obtained photocatalyst. The pore size and the total volume of pores were calculated by the Barrett-Joyner-Halenda (BJH) method, using the Halsey equation. Prior to the measurement, the sample was degassed at $120^{\circ} \mathrm{C}$ for $24 \mathrm{~h}$.

\section{Photocatalytic degradation experiment}

Photoactivity tests were performed in a UV-RS2 laboratory reactor (Heraeus, Hanau, Germany) equipped with a 150-W medium-pressure mercury lamp as a UV light source, surrounded by a water cooling quartz jacket, at room temperature. In the experiment, the photocatalyst $(200 \mathrm{mg})$ was suspended in $200 \mathrm{~mL}$ of selected surfactant solution at an initial concentration of $10 \mathrm{mg} / \mathrm{L}$. The catalyst concentration was experimentally selected as most effective, (see SI). First, the surfactant solution and photocatalyst were magnetically stirred using an R05 IKAMAG magnetic stirrer (IKA Werke $\mathrm{GmbH}$, Staufenim Breisgau, Germany) in darkness for 30 min to reach the adsorption/desorption equilibrium prior to UV-Vis irradiation. After equilibrium was reached, the concentration of surfactants was measured and the radiation was then turned on to initiate the photocatalytic reaction. In the next step, the irradiated mixtures $(8 \mathrm{~mL})$ were collected from the reactor at intervals $(1,5,10,20,30,40,50$, $60 \mathrm{~min}$ ) and centrifuged at 12,000 rpm (MPW-352, MPW MED. Instruments, Warsaw, Poland) to remove the photocatalyst nanoparticles.

\section{Spectrophotometric analysis}

The concentration of non-ionic surfactants after adsorption and UV irradiation was analyzed by means of the iodobismuthate method with final measurement of absorbance of the bismuth-thiourea complex (BiAS-thio), based on the precipitation of oxyethylate with Dragendorff's reagent (Cierniak et al. 2020). The precipitate dissolved with the simultaneous formation of the bismuth-thiourea complex, the absorbance of which was proportional to the surfactant content of the sample tested. The modified Dragendorff's solution (iodide bismuth(III) complex in the presence of barium ions) was prepared by dissolving in a $1000 \mathrm{~mL}$ volumetric flask $1.2 \mathrm{~g}$ basic bismuth(III) nitrate, $150 \mathrm{~mL}$ glacial acetic acid, $50 \mathrm{~g}$ potassium iodide, $100 \mathrm{~g}$ barium chloride and $5 \mathrm{~g}$ of anhydrous sodium phosphate in approx. $300 \mathrm{~mL}$ of demineralized water. After the solids had dissolved, the flask was filled to volume with demineralized water. Before use, the solution was filtered through a medium filtration paper filter. A complexing-dissolution solution (100 mL) was prepared by dissolving $15 \mathrm{~g}$ of thiourea and $6.9 \mathrm{~mL}$ of concentrated nitric acid (65\%) in water $(15 \%$ thiourea in 
$\left.1 \mathrm{M} \mathrm{HNO}_{3}\right) .1 \mathrm{~mL}$ of modified Dragendorff's reagent was added to an $8 \mathrm{~mL}$ centrifuge tube containing $0.1 \mathrm{~mL}$ of test sample. Then, after precipitation of oxyethylates, the precipitate was centrifuged for $5 \mathrm{~min}$ in a high-speed centrifuge at 12,000 rpm (MPW-352, MPW MED. Instruments, Warsaw, Poland), the supernatant was drained as waste, and the remaining precipitate was washed with glacial acetic acid (3 $\times 1 \mathrm{~mL}$ ) to wash away the residual Dragendorff's reagent. Next, $2 \mathrm{~mL}$ of the complexing solution was added to the isolated precipitate of oxyethylate with Dragendorff's reagent. Then, the absorbance of the solution at $\lambda=468 \mathrm{~nm}$ was measured using a UV-Vis spectrophotometer (V-530, Jasco, Hachioji City, Japan) using water as a reference. Based on the obtained results, the efficiency of surfactant degradation was determined (percentage removal of analyte from the solution) using formula (2):

$$
\text { Degradation }(\%)=\left[\left(C_{0}-C_{t}\right) / C_{0}\right] \cdot 100 \%
$$

where $\mathrm{C}_{0}$ is the surfactant concentration before the degradation process, $\mathrm{mg} / \mathrm{L}$, and $\mathrm{C}_{\mathrm{t}}$ is the surfactant concentration in samples collected during the degradation process, $\mathrm{mg} / \mathrm{L}$.

\section{Liquid chromatography-mass spectrometry}

Identification of degradation products was performed using the UltiMate 3000 HPLC from Dionex (Sunnyvale, CA, USA) connected with the 4000 QTRAP mass spectrometer from ABSciex (Foster City, CA, USA). Exactly $5 \mu \mathrm{L}$ samples were injected into a Gemini-NX C18 column (100 mm ' 2.0 mm I.D.; $3 \mu \mathrm{m}$ ) from Phenomenex (Torrance, CA, USA) maintained at $35^{\circ} \mathrm{C}$. The mobile phase consisted of $5 \mathrm{mM}$ ammonium acetate in water and methanol at a flow rate of $0.3 \mathrm{~mL} \mathrm{~min}^{-1}$ in a gradient from 70 to $95 \%$ methanol in 3 minutes and then 3 minutes in isocratic conditions. The electrospray (ESI) ion source operated in a positive mode. Nitrogen was used in both the source and the mass spectrometer. The following parameters of the ESI source and mass spectrometer were used: curtain gas pressure $20 \mathrm{psi}$, nebulization gas pressure $40 \mathrm{psi}$, auxiliary gas pressure $40 \mathrm{psi}$, source temperature $350^{\circ} \mathrm{C}$, ESI voltage $4500 \mathrm{~V}$, declustering potential $50 \mathrm{~V}$, entrance potential $10 \mathrm{~V}$. Chromatograms were collected in the Q1 mass spectra mode in a 100-1200 $\mathrm{m} / \mathrm{z}$ range.

\section{Results and discussion}

\section{Characterization of synthesized ZnO}

Zinc oxide nanoparticles have received substantial attention in a wide range of practical applications due to their exceptional properties. One of them is application as an alternative photocatalyst to $\mathrm{TiO}_{2}$ (Kołodziejczak-Radzimska and Jesionowski 2014). Zinc oxide possess the same band gap energy $(3.37 \mathrm{eV})$ as $\mathrm{TiO}_{2}$, while its absorption efficiency across a large fraction of the solar spectrum is higher (Ong et al. 2018; Özgür et al. 2018). Furthermore, according to the literature reports (Kołodziejczak-Radzimska and Jesionowski 2014; Ong et al. 2018), the production costs of $\mathrm{ZnO}$ are ca. $75 \%$ lower than in case of $\mathrm{TiO}_{2}$. The photocatalytic properties of $\mathrm{ZnO}$ are closely associated with its crystal structure. Zinc oxide is a compound that possesses a tetrahedral bonding configuration corresponding to the $\mathrm{sp}^{3}$ covalent bonding (Ong et al. 2018; Özgür et al. 2018), but this material also exhibits a substantial ionic character that tends to increase the bandgap beyond the expected from the covalent bonding (Özgür et al. 2018). ZnO can form crystals in three different forms: hexagonal wurtzite, cubic zinc blende and rock salt (Özgür et al. 2018). The phase and crystal parameters of the obtained zinc oxide nanoparticles were investigated by X-ray diffraction pattern presented in Fig. 1a. The registered diffractogram corresponds with the lines of $\mathrm{ZnO}$ wurtzite (hexagonal) matching with the database JCPDS card No. 36-1451 in line with the previously reported data (Dimapilis et al. 2018, van Heerden and Swanepoel 1997). The sharpness and strong intensity of recorded diffractions indicate that the synthesized $\mathrm{ZnO}$ sample is well crystallized and has a polycrystalline structure, with a (101) preferred orientation. The calculated average size of the obtained $\mathrm{ZnO}$ crystallites was $40.5 \mathrm{~nm}$. It should be noted that the crystallite size is assumed to be the size of a coherently diffracting domain and it is not reflecting the particle size (Bindu\&Thomas 2014). Therefore, further observations with SEM and TEM were necessary and will be discussed in the next paragraphs.

Figure $1 \mathrm{~b}$ presents the FT-IR spectrum of as-obtained $\mathrm{ZnO}$ nanoparticles. The broad absorption bands at 3438 $\mathrm{cm}^{-1}$ and $\sim 1630 \mathrm{~cm}^{-1}$ are assigned to the vibration of the hydroxyl groups, most likely resulting from the re-absorption of water molecules from ambient atmosphere (Krishnakumar et al. 2009). The band registered at $1558 \mathrm{~cm}^{-1}$ corresponds to the asymmetric stretching of the carboxyl group, resulting from small amounts of residual, unreacted zinc acetate. The sharp peak located at $530 \mathrm{~cm}^{-1}$ is atypical band of the wurtzite hexagonal phase of pure $\mathrm{ZnO}$ (Krishnakumaret et al. 2009).

XPS is an effective tool for analyzing the chemical states of constituent elements. Therefore, the $\mathrm{ZnO}$ nanoparticles were also analyzed by X-ray photoelectron spectroscopy (XPS). The Zn 2p core-level (Fig. 2a) of the prepared $\mathrm{ZnO}$ nanoparticles has four fitting peaks. The peaks located at approx.1044.2 and $1021.1 \mathrm{eV}$ are attributed to $\mathrm{Zn} 2 \mathrm{p}_{1 / 2}$ and $\mathrm{Zn} 2 \mathrm{p}_{3 / 2}$, respectively. Symmetrical shape of the $\mathrm{Zn} 2 \mathrm{p}$ spectra and their small half-width values (1.58 and $1.53 \mathrm{eV}$, respectively) indicate that $\mathrm{Zn}^{2+}$ ions 
Fig. 1 a X-ray diffraction pattern of the prepared zinc oxide nanoparticles; b FT-IR spectrum of the prepared zinc oxide nanoparticles

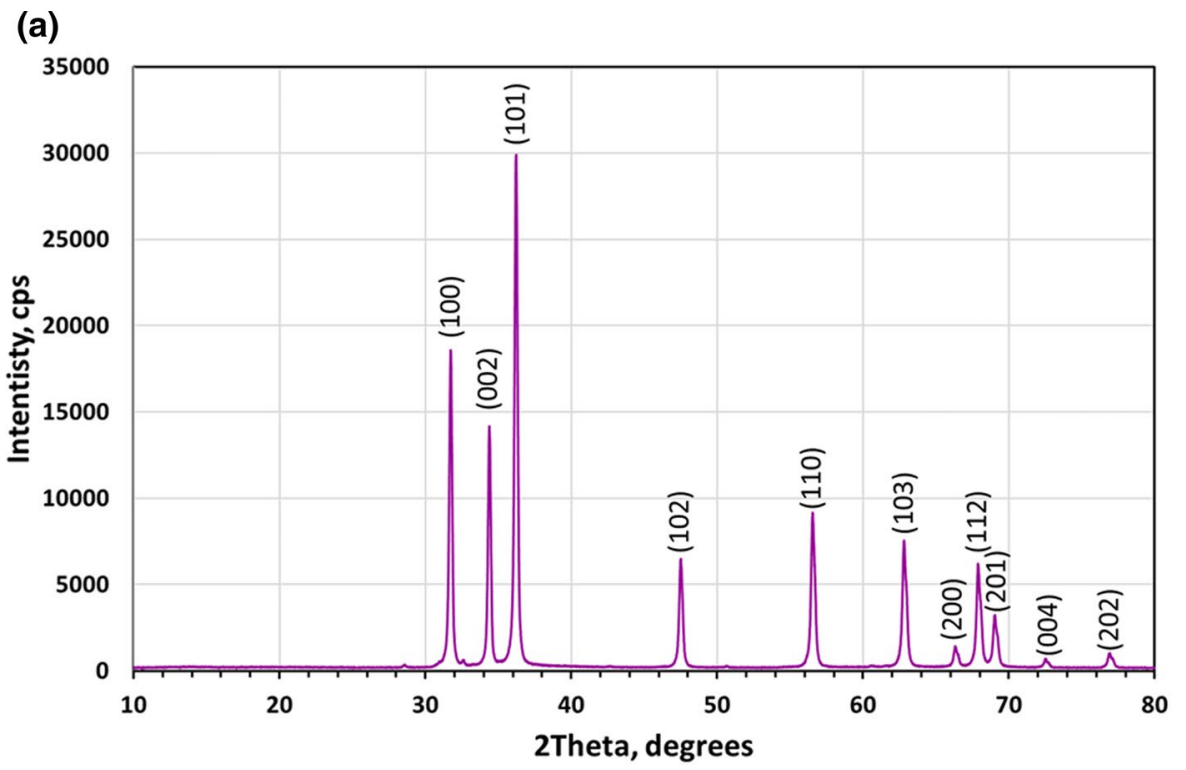

(b)

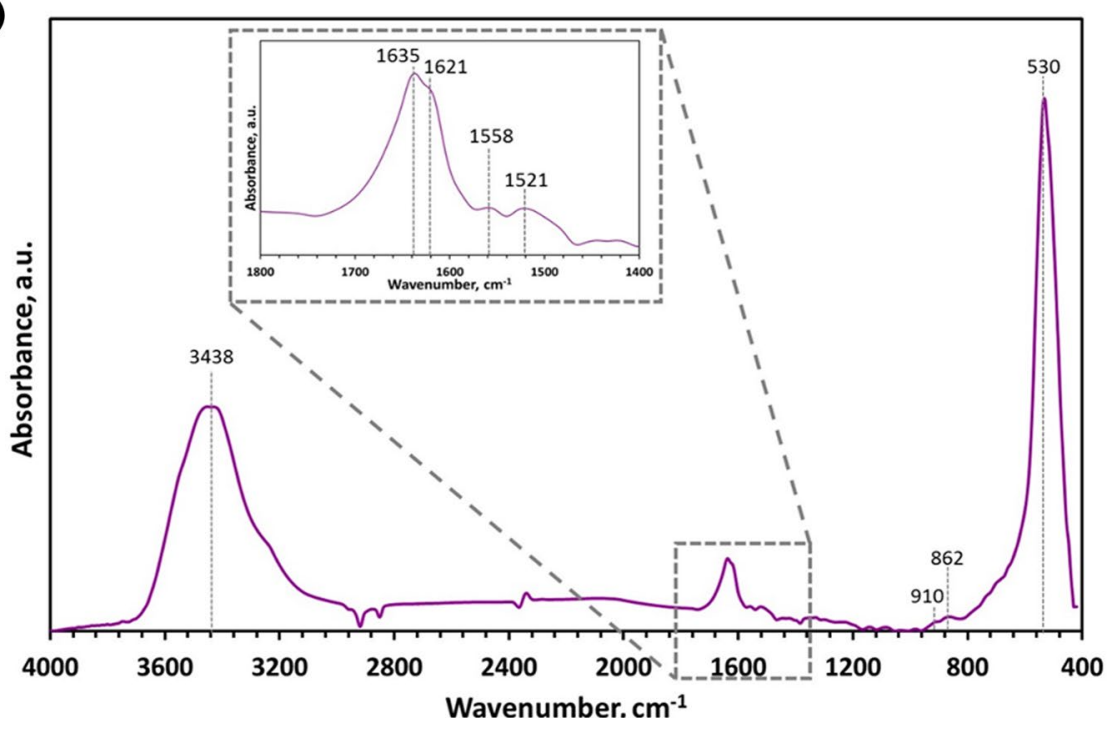

are in a tetrahedral oxygen environment and the chemical $\mathrm{Zn}-\mathrm{O}$ bonds are dominant in the studied nanoparticles (Al-Gashani et al. 2013). Higher binding energy at $\mathrm{Zn} 2 \mathrm{p}$ (peaks located at about 1045.5 and $1022.3 \mathrm{eV}$ ) is associated with the presence of $\mathrm{Zn}-\mathrm{OH}$ groups on the sample surface. The O 1s core-level spectrum (Fig. 2b) of $\mathrm{ZnO}$ nanoparticles shows three different forms of oxygen. Two fitting Gaussians peaks located at 529.8 and $531.2 \mathrm{eV}$ can be attributed to $\mathrm{O}^{2-}$ ions in the $\mathrm{Zn}-\mathrm{O}$ bonding of the wurtzite structure of $\mathrm{ZnO}$ and to the $\mathrm{Zn}-\mathrm{OH}$ bonding, respectively (Al-Gashani et al. 2013). The peak located at $530.5 \mathrm{eV}$ is characteristic for the presence of $\mathrm{C}=\mathrm{O}$ groups most likely associated with the presence of adventitious carbon, which is usually found on the surface of most air exposed samples. The presence of adventitious carbon is also confirmed by the C 1 s core-level spectrum (Fig. 2c).

The SEM and TEM observations (Fig. 3 a,b) were necessary to determine the structure; morphology and particle size of obtained $\mathrm{ZnO}$ nanoparticles. Both SEM and TEM images of obtained synthesized photocatalyst confirm that it exhibits a uniform, spherical shape with the particle size fluctuating between 90 and $130 \mathrm{~nm}$ and possesses a tendency for aggregation and formation of larger conglomerates. To further confirm the chemical composition of the $\mathrm{ZnO}$ nanoparticles, an EDS analysis shown in Fig. 3c was carried out, which revealed only the presence of $\mathrm{Zn}$ and $\mathrm{O}$ elements. As a less sensitive technique than XPS, it strongly confirms that the carbon detected by XPS is adventitious. 

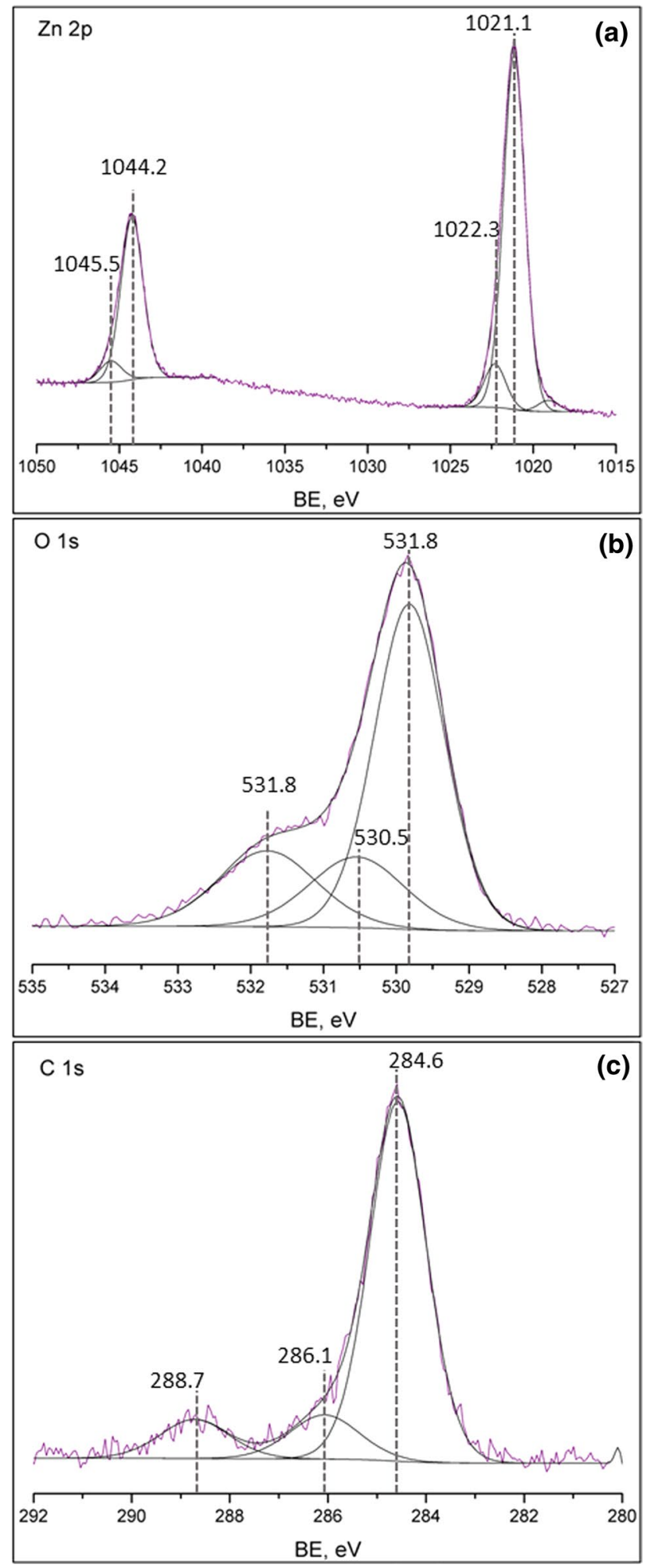

Fig. 2 XPS spectra of Zn 2p a; O 1s b and C 1s $\mathbf{c}$ registered for synthesized $\mathrm{ZnO}$ nanoparticles
To assess the parameters of the porous structure of the $\mathrm{ZnO}$ photocatalyst, the $\mathrm{N}_{2}$ adsorption/desorption was recorded (Fig. 4). In accordance with the IUPAC classification, the registered isotherm is classified as type IV isotherm with an $\mathrm{H} 3$ type hysteresis loop $\mathrm{p} / \mathrm{p}_{0}=0.45-0.99$. This means that the sample has a mesoporous texture, tendency to aggregate and slit-shaped pores (Cychosz\&Thommes 2018). The specific surface area calculated by the BET method is equal to $9.64 \mathrm{~m}^{2} / \mathrm{g}$, while the total pore volume is $0.55 \mathrm{~cm}^{3} / \mathrm{g}$ and average pore diameter is equal to $21.27 \mathrm{~nm}$. The obtained $\mathrm{ZnO}$ characteristics correspond with the previous studies by Tian et al. (2012) and Pourrahimi et al. (2016).

\section{Degradation of surfactants}

The removal efficiency of selected surfactants under UV irradiation $(150 \mathrm{~W})$ with and without the presence of $\mathrm{ZnO}$ nanoparticles is presented in Fig. 5. The calculated noncatalytic removal efficiency of octylphenol ethoxylate (Triton $\mathrm{X}-100)$ was equal to $18 \%, 7 \%$ of which was caused by adsorption of this compound on the photoreactor surface. Correspondingly, low removal efficiency (equal to $10 \%, 4 \%$ of which was adsorbed on the photoreactor surface) was calculated for dodecyl alcohol ethoxylate $\left(\mathrm{C}_{12} \mathrm{E}_{10}\right)$. Addition of $200 \mathrm{mg}$ of $\mathrm{ZnO}$ nanoparticles significantly improved the removal efficiency for both tested surfactants. The maximal removal efficiencies, achieved after only $1 \mathrm{~h}$ of UV irradiation, were equal to $82 \%$ and $92 \%$, for Triton X-100 and $\mathrm{C}_{12} \mathrm{E}_{10}$, respectively. Removal of surfactants from the aqueous environment during photodegradation is based on several indirect processes: (i) diffusion of surfactants from the solution to the zinc oxide surface (external mass transport), (ii) their diffusion between or inside the catalyst particles to its active surface (internal mass transport); (iii) adsorption of surfactants on photon-activated zinc oxide surface, photodegradation reaction of the adsorbed phase on the zinc oxide surface, desorption of intermediate products from the $\mathrm{ZnO}$ surface and transfer of primary photodegradation products from the interface to the liquid phase. Results presented in Fig. 5a indicate that the removal of Triton X-100 from the aqueous solutions is mainly caused by the adsorption of this compound on the catalyst surface ( $60 \%$ of the removal efficiency) with slight effect of photocatalytic oxidation (22\%). In contrast, adsorption of dodecyl alcohol ethoxylate $\left(\mathrm{C}_{12} \mathrm{E}_{10}\right)$ was equal to $20 \%$, while photodegradation process reached $72 \%$, which contributes to a total removal efficiency of $92 \%$ (Fig. 5b). 

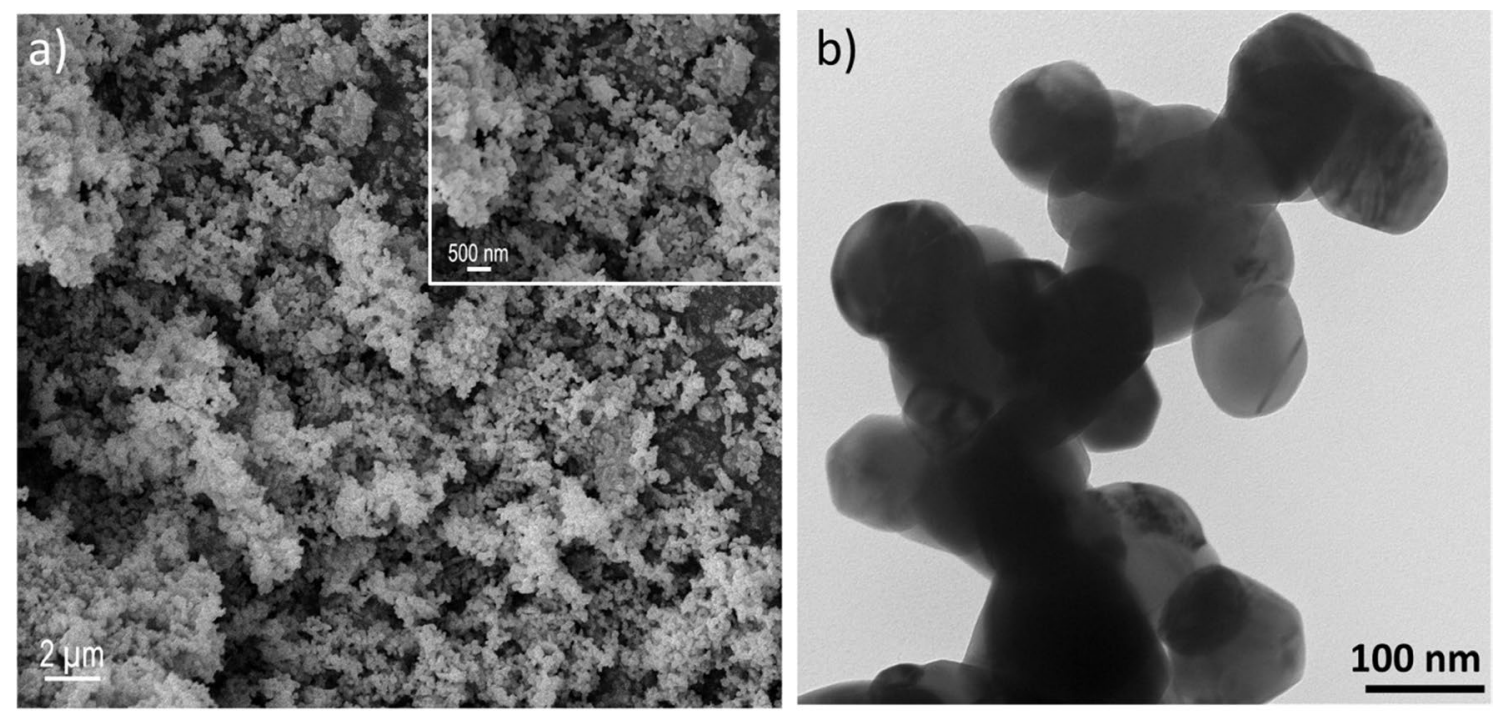

c)

Integral Counts: 177607

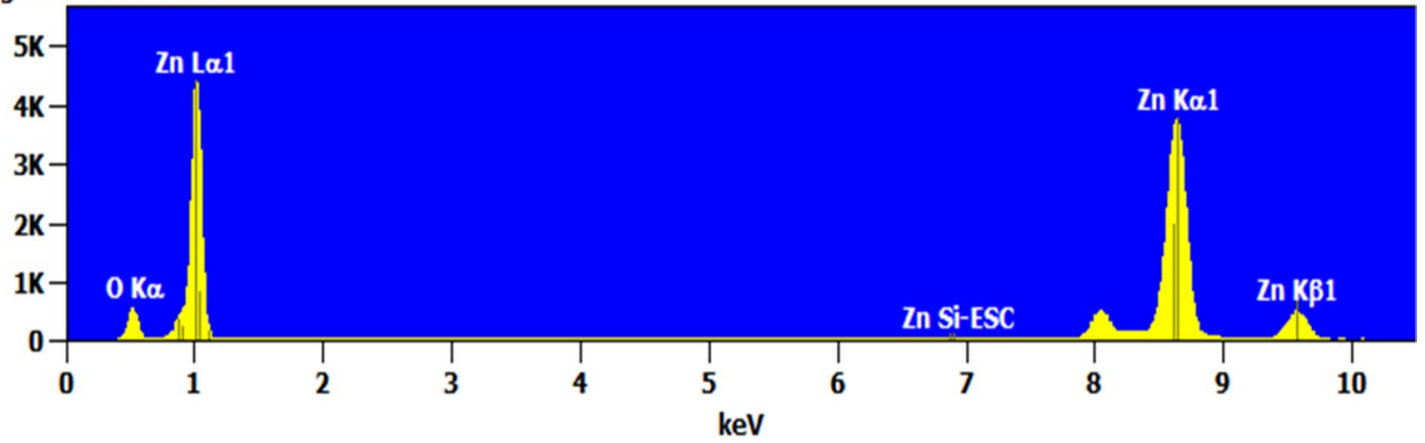

Fig. 3 SEM a; TEM $\mathbf{b}$ images and EDS spectrum $\mathbf{c}$ of synthesized $\mathrm{ZnO}$ nanoparticles

Fig. $4 \mathrm{~N}_{2}$ adsorption/desorption isotherms of $\mathrm{ZnO}$ nanoparticles

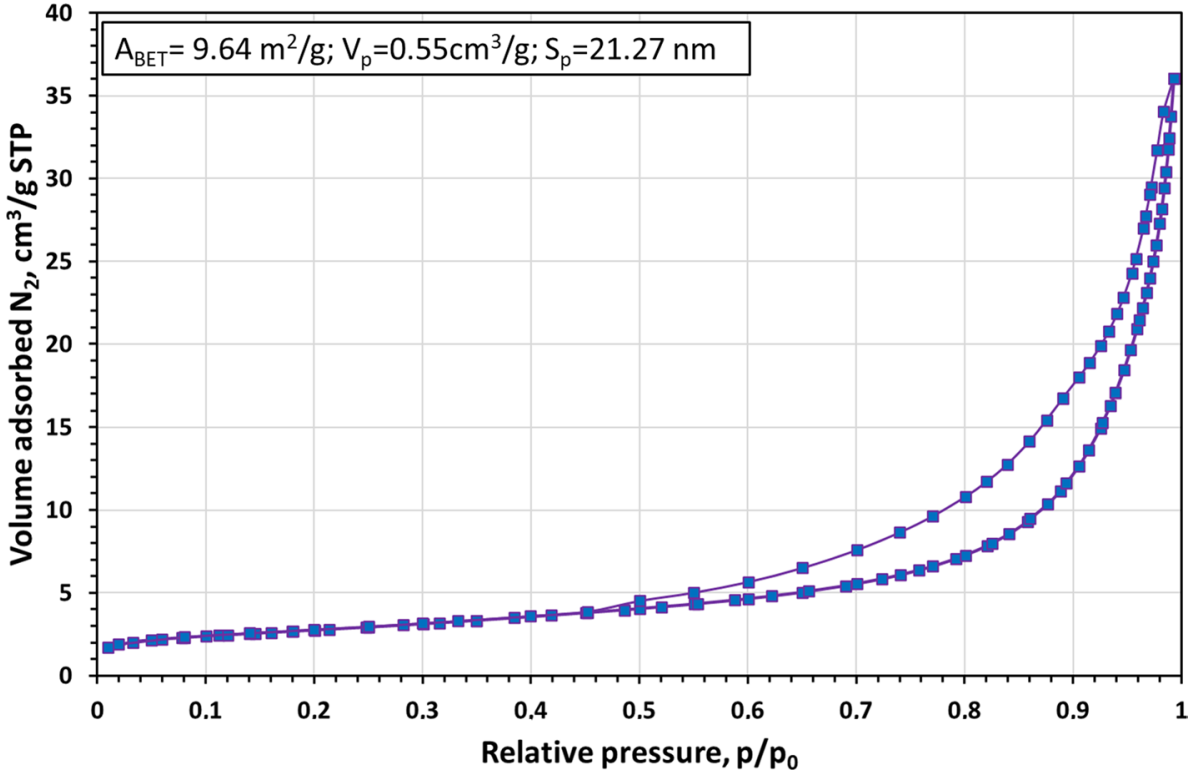

Springer 
Fig. 5 Removal efficiency of a octylphenol ethoxylate (Triton $\mathrm{X}-100)$ and b dodecyl alcohol ethoxylate $\left(\mathrm{C}_{12} \mathrm{E}_{10}\right)$ under UV irradiation with (violet, squares) and without $\mathrm{ZnO}$ (orange, circles).
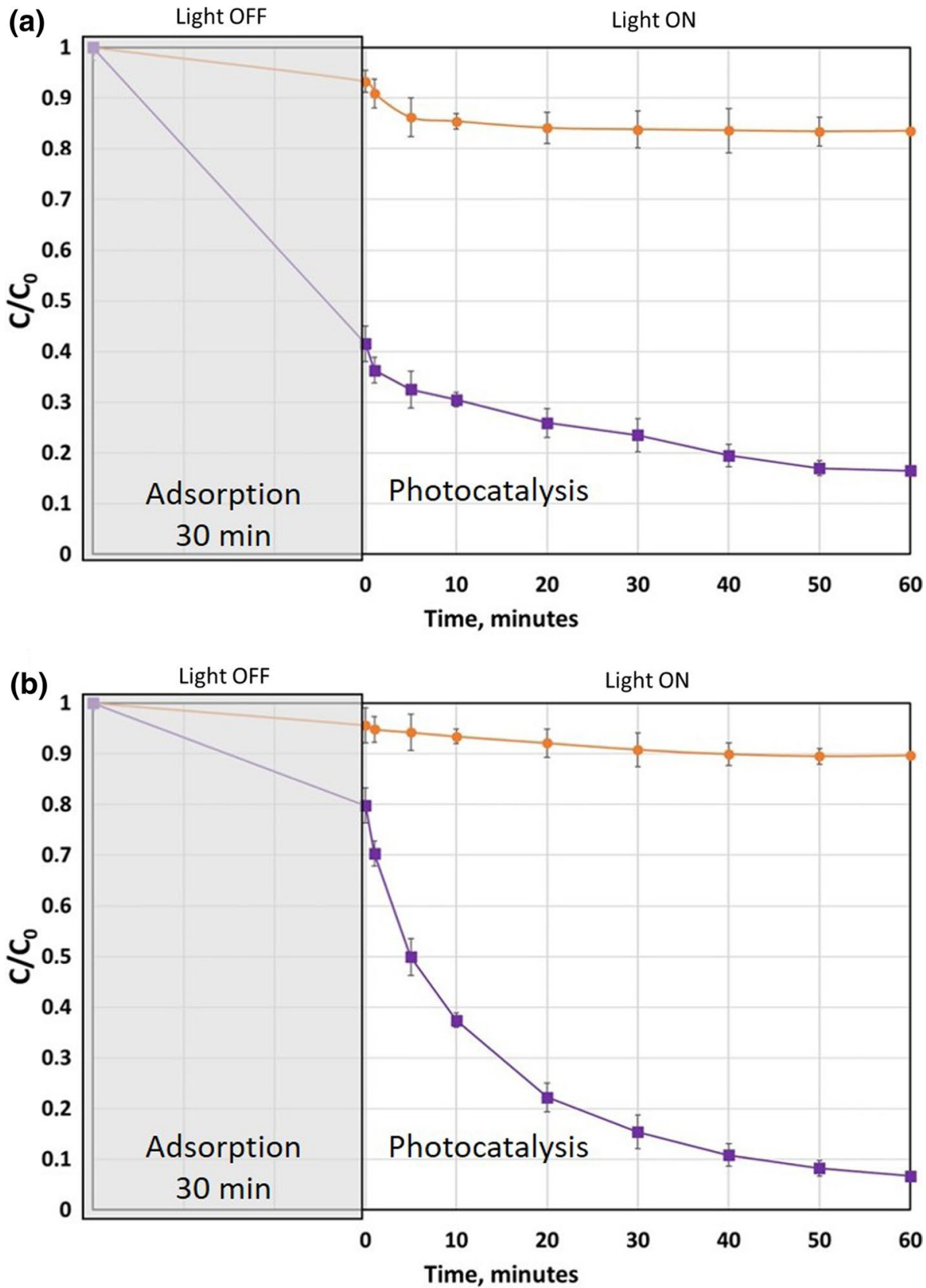

The number of catalyst active sites occupied by the substrate is expressed by fractional occupancy of the adsorption sites $\theta$ which is defined as the ratio of the amount of substrate adsorbed on the catalyst to the maximum number of molecules that can be adsorbed on a given mass of $\mathrm{ZnO}$ catalyst. In mathematical terms, it is defined by the use of initial substrate concentrations $C_{\text {init }}$, the equilibrium concentrations $C_{\text {equil }}$ and the amount of catalyst per unit amount of solution $C_{c a t}(3)$. The $\theta$ depends on the concentration of the substrate in the region of catalyst reaction. It can be defined by the Langmuir adsorption isotherm at a constant temperature by taking into account the following assumptions: the catalyst adsorption sites on the surface are evenly distributed and their number is limited, adsorption site has the ability to adsorb only one molecule, the adsorption takes place in catalyst monolayer only adsorbed particles do not interact each other.

$\theta=\frac{C_{\text {init }}-C_{\text {equil }}}{C_{\text {cat }}}$ 
In order to estimate the kinetic constants of the Langmuir-Hinshelwood kinetic model (4), $K$-Langmuir adsorption constant, and $k_{\tau}$-rate of the adsorption constant, the least squares method was used. This is the classic approach in regression analysis to bring the model closer to the value of the experiment by minimizing the sum of the squares of the residuals calculated for each measurement. For this purpose, the differential kinetic equation is embedded in the method of minimizing the least squares.

$r=-\frac{d C}{d t}=\frac{k_{\tau} K \cdot C}{1+K \cdot C}=k_{\tau} \theta$

The least squares method requires multiple, iterative calculations of the fitting function (4), at points corresponding to the positions of the experimental values. For this purpose, numerical integration of the above differential kinetic equation is carried out using the classic Adams-Bashforth method in the range between the initial integration time 0 to the time corresponding to the given experimental value. The residual sum minimization algorithm can then calculate the square of the distance for a given point and consequently the sum of all squares. The sum defined in this way is then minimized by the Levenberg-Marquardt algorithm by successive stepwise adjustments of the searched parameters $k_{\tau}$ and $K$.

The comparative study for the reaction without catalyst follows typical equilibrium reaction path. With the assumption of equimolar reaction, the kinetic equation for equilibrium system reads:

$r=-\frac{d C}{d t}=-k_{1} C+\frac{k_{1}}{K_{e q}}\left(C_{\text {init }}-C\right)$

The algorithm of estimating the rate constant $k_{1}$ and equilibrium constant $K$ is exactly the same as for the adsorption case discussed earlier in the text.

The results obtained for all $\mathrm{C}_{12} \mathrm{E}_{10}$ and Triton X-100 cases clearly indicate correctness of the applied assumptions. For reactions without $\mathrm{ZnO}$ catalyst, the reactions exhibit equilibrium type (5), while the photodegradation catalyzed with $\mathrm{ZnO}$ follows the Langmuir-Hinshelwood model (2). The table below shows the individual results obtained for the respective constants for the above-mentioned reactions. The statistical quality of the fit is measured with the minimized value of the residual sums $R$. The obtained $R$-values, which are small compared to the square of the absolute values, indicate that the obtained models are of good quality and correctly reflect the analyzed photodegradation processes.

The models fit to the experimental results are presented on two figures for catalyzed and non-catalyzed reactions. The relative fractional occupancy of the adsorption sites $\theta$ is presented on separate graphs (Fig. 6ab) for clarity of presentation. It is visible that the coverage decreases during the process which corresponds to the decreasing substrate concentrations.

Comparative analysis of the kinetic parameters of photodegradation process for both surfactants revealed that the photodegradation rate in the case of $\mathrm{C}_{12} \mathrm{E}_{10}$ increases significantly, in comparison with Triton X-100 (Tables 1 and 2).

The observed difference in photodegradation rate may be due to the branched hydrocarbon chain, which increases the resistance to photocatalytic oxidation. On the other hand, dodecyl alcohol ethoxylate $\left(\mathrm{C}_{12} \mathrm{E}_{10}\right)$ possesses a straight hydrocarbon chain, which undergoes efficient photodegradation (Figs. 5, 7). Similar behavior is observed for the completely different biodegradation processes using microorganisms, in case of which the biological oxidation processes of non-ionic surfactants usually shorten the oxyethylene chain by $2-3$ units with the formation of a homologue series. Further metabolism is associated with the degradation of the alkyl group and finally with ring cleavage (Ding et al. 1996; Staples et al. 2001).

The LC-MS/MS analysis was carried out to obtain information regarding compounds formed during the photodegradation of both non-ionic surfactants. Figure 8 presents the spectra of two surfactants subjected to the tests and products resulting from their photodegradation. Spectra of Triton $\mathrm{X}-100$ and its degradation products are presented on the left side of Fig. 8, whereas spectra of dodecyl alcohol ethoxylate $\left(\mathrm{C}_{12} \mathrm{E}_{10}\right)$ on the right side. The degradation products were studied after 30 and 60 minutes. Similar products have been identified in all tests although at different intensities. Triton X-100 contains homologues which include from $n$ $=2(\mathrm{~m} / \mathrm{z} \mathrm{312})$ to $n=21(\mathrm{~m} / \mathrm{z} 1060)$ ethoxy groups in the molecule, as can be seen in the spectrum (Fig. 8a), while $\mathrm{C}_{12} \mathrm{E}_{10}$ contains homologues which include from $n=3(\mathrm{~m} / \mathrm{z}$ $336)$ to $n=21(\mathrm{~m} / \mathrm{z} 1128)$ ethoxy groups (Fig. 8b). The peaks differ from each other by $44 \mathrm{Da}$, which indicates the difference of a single ethoxy unit. The peak series in each homologue can be identified as the $\mathrm{NH}_{4}$ adducts. The next sections in Fig. 8 present the spectra of products formed during photodegradation. Triton $\mathrm{X}-100$ and $\mathrm{C}_{12} \mathrm{E}_{10}$ oxidized to their carboxylic acid derivatives are presented in Fig. $8 \mathrm{~b}$, $\mathrm{f}$, respectively. Series of homologues from $\mathrm{m} / \mathrm{z} 370(n=3)$ to $\mathrm{m} / \mathrm{z} 810(n=13)$ and from $\mathrm{m} / \mathrm{z} 350(n=3)$ to $\mathrm{m} / \mathrm{z} 966$ $(n=17)$ were found for oxidized Triton X-100 and $\mathrm{C}_{12} \mathrm{E}_{10}$, respectively. The last four spectra (Fig. 8c, d, g, h) indicate the presence of polyethylene glycol and its oxidized form with the carboxylic group on one side of the chain. The presence of polyethylene glycol among photodegradation products suggests that the parent molecules (both octylphenol ethoxylate and dodecyl alcohol ethoxylate) were possibly cleaved into the hydrophobic and hydrophilic part, as was the case described in the report of Zhang and Wan (2014) regarding the photodegradation of Triton X-100 using $\mathrm{TiO}_{2}$. 
Fig. 6 Coverage fraction of catalyst $\theta$ for the case with a Triton X-100 and $\mathbf{b} \mathrm{C}_{12} \mathrm{E}_{10}$.

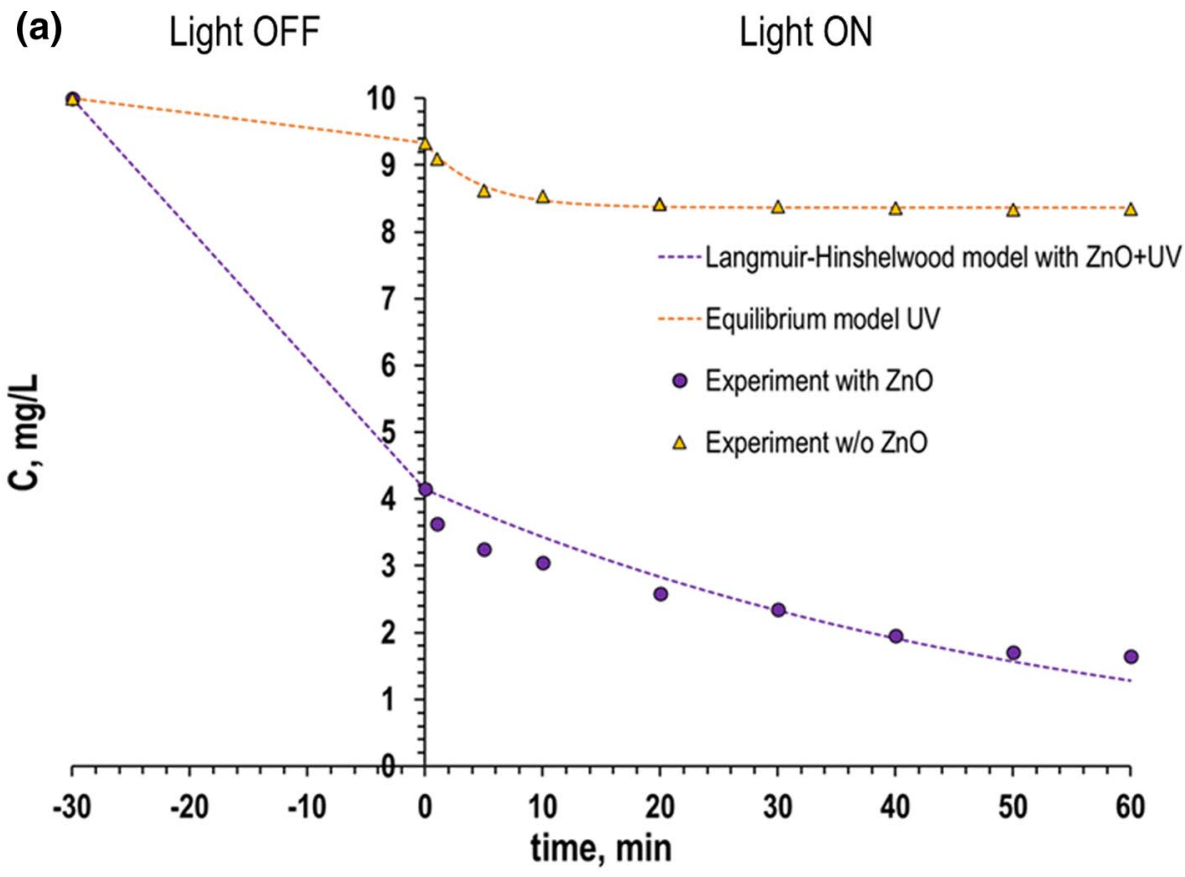

(b) Light OFF Light ON

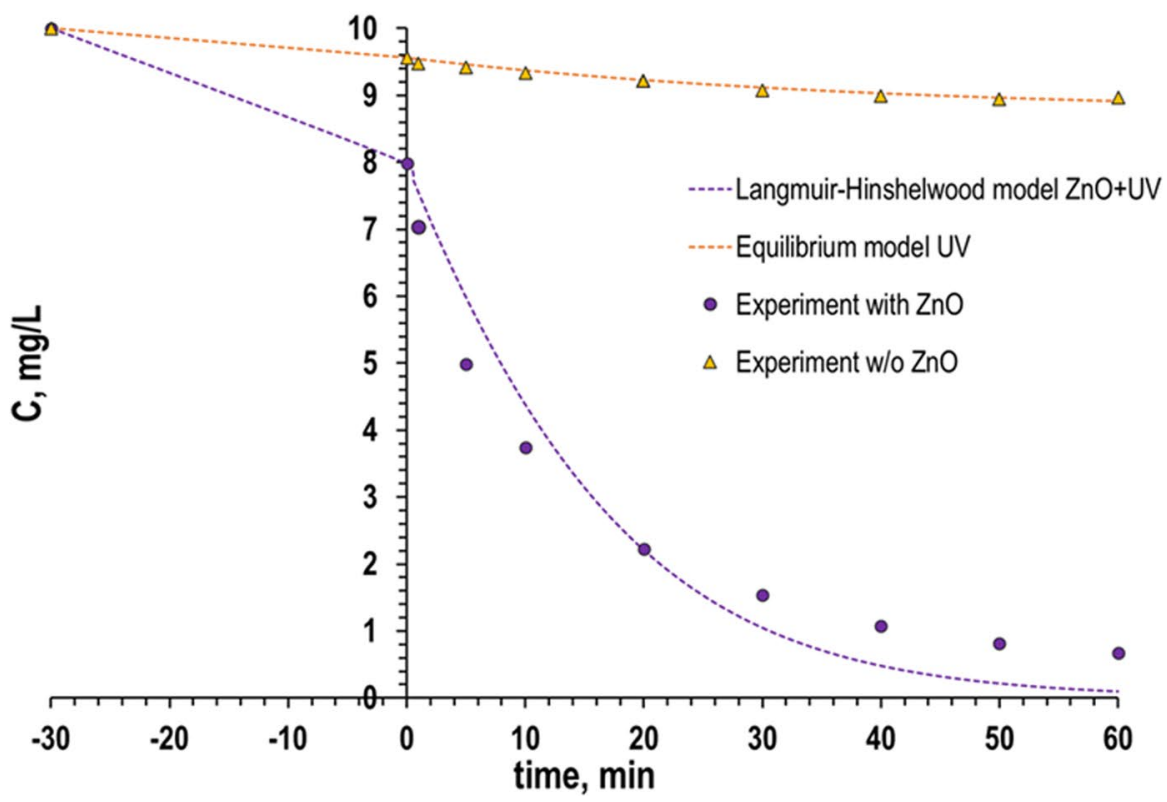

Table 1 Results for the reaction catalyzed with $\mathrm{ZnO}$ according to Langmuir-Hinshelwood model

\begin{tabular}{llll}
\hline Substance & $k_{\tau}$ & $K$ & $R$ \\
\hline $\mathrm{C}_{12} \mathrm{E}_{10}$ & 1.348 & $6.061 \cdot 10^{-2}$ & 2.994 \\
Triton X-100 & $7.411 \cdot 10^{-1}$ & $2.814 \cdot 10^{-2}$ & $8.35 \cdot 10^{-1}$ \\
\hline
\end{tabular}

Table 2 Results for the non-catalyzed, comparative reaction according to equilibrium model

\begin{tabular}{llll}
\hline Substance & $k_{1}$ & $K$ & $R$ \\
\hline $\mathrm{C}_{12} \mathrm{E}_{10}$ & $2.243 \cdot 10^{-3}$ & $9.377 \cdot 10^{-2}$ & $1.251 \cdot 10^{-2}$ \\
Triton X-100 & $2.248 \cdot 10^{-2}$ & $1.15 \cdot 10^{-1}$ & $1.43 \cdot 10^{-2}$ \\
\hline
\end{tabular}


Fig. 7 Langmuir-Hinshelwood model for catalyzed and comparative non-catalyzed model for photodegradation of a Triton $\mathrm{X}-100$ and $\mathbf{b} \mathrm{C}_{12} \mathrm{E}_{10}$
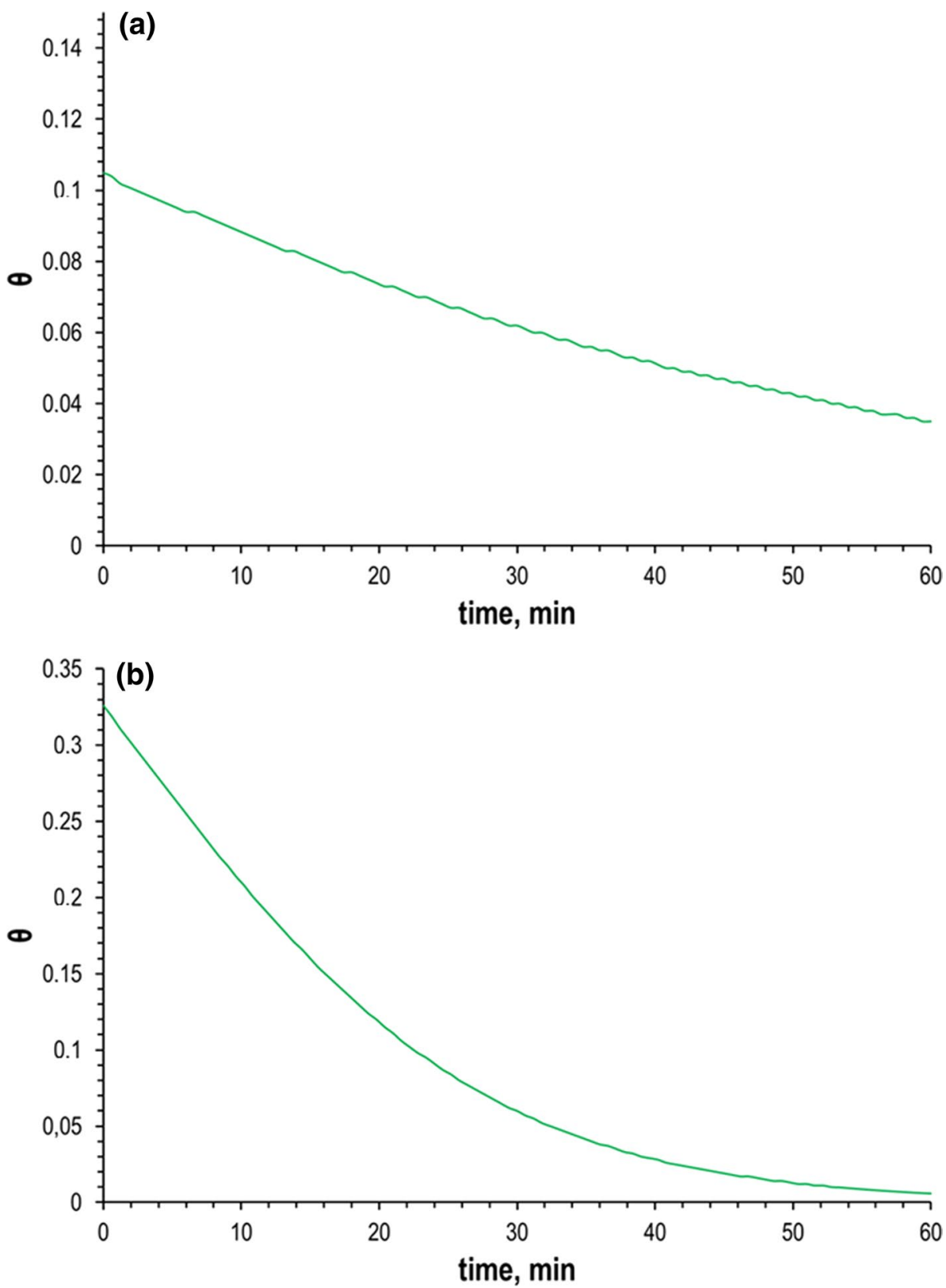

Photocatalytic degradation of non-ionic surfactants can proceed in three main stages: (i) adsorption of surfactant molecules on the $\mathrm{ZnO}$ surface, (ii) fast photoinduced steps (electron-hole pairs formation, generation of reactive oxygen species), (iii) slow dynamic steps (gradual transformation of organic molecules to simpler forms and their final mineralization) (Hoffmann et al. 1995; Hidaka et al. 1992a, b). As it is shown in Fig. $9 \mathrm{ZnO}$ photocatalyst absorbs UV light with energy above band gap of $3.37 \mathrm{eV}$. The absorption of photon excites an electron to the conduction band
$\left(\mathrm{e}_{\mathrm{CB}}{ }^{-}\right)$and simultaneously generates a positive hole in the valence band $\left(\mathrm{h}_{\mathrm{VB}}{ }^{+}\right)$(eq. 6). Another consequence of the second stage is the migration of charge carriers to the photocatalyst surface to initiate redox reactions with adsorbate molecules (Hoffmann et al. 1995; Hoffmann et al. 1994; Pelaez et al. 2012). Holes $\left(\mathrm{h}_{\mathrm{VB}}{ }^{+}\right)$can oxidize $\mathrm{H}_{2} \mathrm{O}$ or $\mathrm{OH}^{-}$ to produce hydroxyl radicals with high redox potential $(2.8$ V) (eq. 7, 8). Electrons $\left(\mathrm{e}_{\mathrm{CB}^{-}}{ }^{-}\right)$located in the conduction band can be rapidly trapped by oxygen adsorbed on $\mathrm{ZnO}$ surface and its reduction to superoxide radical anion $\left(\mathrm{O}_{2}^{\bullet-}\right)$ 

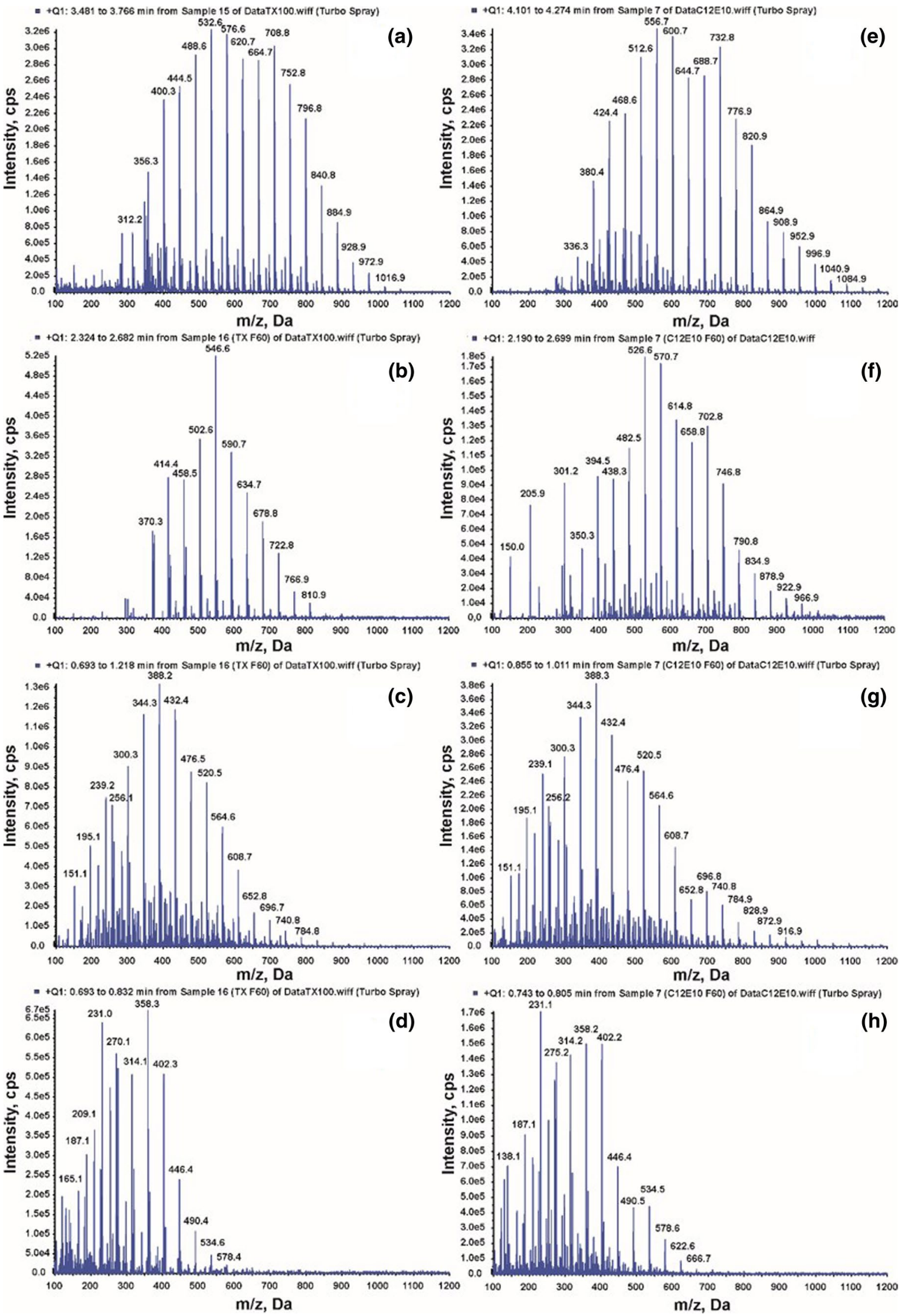
4Fig. 8 Mass spectra of Triton X-100 and its degradation products (left side) as well as dodecyl alcohol ethoxylate $\left(\mathrm{C}_{12} \mathrm{E}_{10}\right)$ and its degradation products (right side) obtained after $60 \mathrm{~min}$ of degradation. Raw surfactants at (a) and (e), carboxy-terminated surfactants at (b) and (f), poly(ethylene glycols) at (c) and (g) and one-side carboxy-terminated poly(ethylene glycols) at (d) and (h)

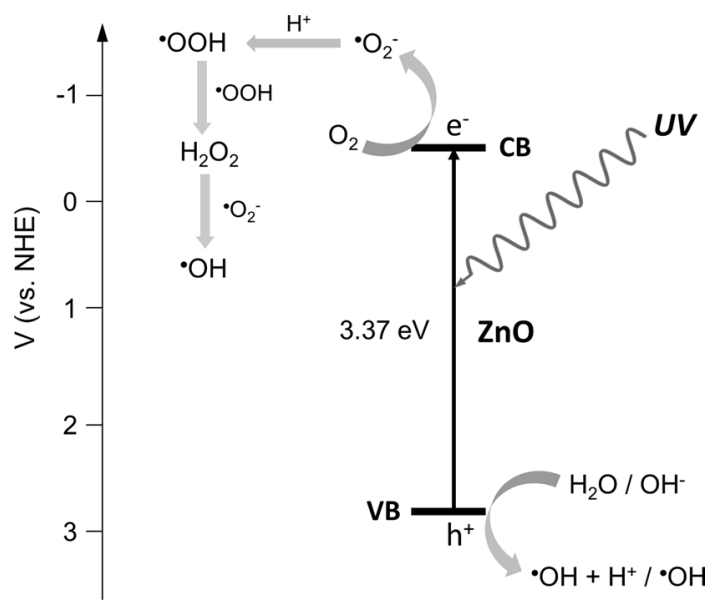

Fig. 9 Schematic diagram of energy band for $\mathrm{ZnO}$ with proposed mechanism of photocatalytic generation of reactive oxygen species participating in surfactant degradation

occurs (eq. 9). This reactive oxygen specimen can further react with $\mathrm{H}^{+}$to form hydroperoxyl radicals (eq. 10) which can then be transformed to $\mathrm{H}_{2} \mathrm{O}_{2}$ (eq. 11). Furthermore, $\mathrm{H}_{2} \mathrm{O}_{2}$ can also react with trapped electrons and superoxide radical anions to form ${ }^{\circ} \mathrm{OH}$ (eq. 12, 13) (Schneider et al. 2014, Giahi et al. 2012). The resulting reactive oxygen species (primarily hydroxyl radicals) can further react (in the third slower stage) with adsorbed surfactant molecules. In the literature, there are available ESR studies about the experimental proof of photoinduced ${ }^{\bullet} \mathrm{OH}$ generation from $\mathrm{ZnO}$ nanoparticles (Yang et al. 2016).

$$
\begin{aligned}
& \mathrm{ZnO}+h n \circledast h_{V B}^{+}+e_{C B}^{-} \\
& \mathrm{H}_{2} \mathrm{O}+h_{V B}^{+} \cdot \mathrm{OH}+H^{+} \\
& \mathrm{OH}^{-}+h_{V B}^{+} \cdot \mathrm{OH} \\
& \mathrm{O}_{2}+e_{\mathrm{CB}}^{-} \mathrm{O}_{2}^{\cdot-} \\
& \mathrm{O}_{2}^{\bullet-}+\mathrm{H}^{+} \cdot \mathrm{OOH}
\end{aligned}
$$

$\cdot \mathrm{OOH}+{ }^{\cdot} \mathrm{OOH} \mathrm{H}_{2} \mathrm{O}_{2}+\mathrm{O}_{2}$

$\mathrm{H}_{2} \mathrm{O}_{2}+e_{\mathrm{CB}}^{-} \cdot \mathrm{OH}+\mathrm{OH}^{-}$

$$
\mathrm{H}_{2} \mathrm{O}_{2}+\mathrm{O}_{2}^{\cdot-\cdot} \mathrm{OH}+\mathrm{OH}^{-}+\mathrm{O}_{2}
$$

In the third (slow dynamic) stage, reactive oxygen species (mainly hydroxyl radicals) participate in oxidation reactions of organic compounds. After addition of ${ }^{\bullet} \mathrm{OH}$ radicals to aromatic groups, the hydroxylated ring is opened and the transformation through hydroxyl intermediates, aldehydes and carboxylic acids, and finally to $\mathrm{CO}_{2}$ can be observed. In the case of alkyl chain, hydroxyl radicals can attack carbon in the $\alpha$ - or $\beta$-position to form peroxides, aldehydes and carboxylic acid derivatives, and then also to cause a final mineralization (Hidaka et al. 1992a, b).

\section{Conclusion}

The experimental data presented in this study confirm that the nanocrystalline, hexagonal $\mathrm{ZnO}$ nanoparticles can be used as a photocatalyst for effective removal of selected non-ionic surfactants from the aqueous environment with removal efficiency $82 \%$ and $92 \%$ for Triton X-100 and $\mathrm{C}_{12} \mathrm{E}_{10}$, respectively. The obtained results clearly show that dodecyl alcohol ethoxylate $\left(\mathrm{C}_{12} \mathrm{E}_{10}\right)$ is more susceptible to photocatalytic degradation than octylphenol ethoxylate (Triton X-100) due to linear molecular structure. The kinetic behavior for photocatalytic degradation of $\mathrm{C}_{12} \mathrm{E}_{10}$ and Triton $\mathrm{X}-100$ on $\mathrm{ZnO}$ nanoparticles can be described in terms of the Langmuir-Hinshelwood model. Identification of photodegradation products by the LC-MS/MS method indicated the mechanism of central fission terminal oxidation, which results in the removal of the hydrophilic part of the surfactant molecule form of poly(ethylene glycols). Such a course of biodegradation has also been found for numerous consortia of microorganisms present in surface waters, sewage and soil. The polydispersity of the non-ionic surfactants used in the study, the structure of the alkyl chain or the length of the oxyethylene chain, did not affect the mechanism of photodegradation, although it did affect their kinetics. This allows to establish that $\mathrm{ZnO}$ nanoparticles can be efficiently applied as an alternative to $\mathrm{TiO}_{2}$.

Supplementary Information The online version contains supplementary material available at (https://doi.org/10.1007/s13762-021-03160-1).

Acknowledgements Authors are thankful for the financial support from the Ministry of Science and Higher Education, Poland, granted 
to Poznan University of Technology (0911/SBAD/0398 and 0912/ SBAD/2006).

Funding This work was financially supported from the Ministry of Science and Higher Education, Poland, granted to Poznan University of Technology (0911/SBAD/0398 and 0912/SBAD/2006).

\section{Compliance with ethical standards}

Conflict of interest None.

Consent to participate All of the co-workers have agreed to participate.

Consent for publication All of the co-workers have agreed to participate.

Open Access This article is licensed under a Creative Commons Attribution 4.0 International License, which permits use, sharing, adaptation, distribution and reproduction in any medium or format, as long as you give appropriate credit to the original author(s) and the source, provide a link to the Creative Commons licence, and indicate if changes were made. The images or other third party material in this article are included in the article's Creative Commons licence, unless indicated otherwise in a credit line to the material. If material is not included in the article's Creative Commons licence and your intended use is not permitted by statutory regulation or exceeds the permitted use, you will need to obtain permission directly from the copyright holder. To view a copy of this licence, visit http://creativecommons.org/licenses/by/4.0/.

\section{References}

Al-Gashani R, Radiman S, Daud AR, Tabet N, Al-Douri Y (2013) XPS and optical studies of different morphologies of $\mathrm{ZnO}$ nanostructures prepared by microwave methods. Ceram Int 39:2283-2292

Babayemi JO, Ogundiran MB, Osibanjo O (2017) Overview of environmental hazards and health effects of pollution in developing countries: a case study of Nigeria. Environ Qual Manag 26:51-71

Bindu P, Thomas S (2014) Estimation of lattice strain in ZnO nanoparticles: X-ray peak profile analysis. J Theor Appl Phys 8:123-134

Byrne JA, Dunlop PSM, Hamilton JWJ, Fernández-Ibáñez P, PoloLópez I, Sharma PK, Vennard ASM (2015) A Review of heterogeneous photocatalysis for water and surface disinfection. Molecules 20:5574-5615

Chen HJ, Tseng DH, Huang SL (2005) Biodegradation of octylphenol polyethoxylate surfactant Triton X-100 by selected microorganisms. Bioresour Technol 96:1483-1491

Cierniak D, Woźniak-Karczewska M, Parus A, Wyrwas B, Loibner AP, Heipieper HJ, Ławniczak Ł, Chrzanowski Ł (2020) How to accurately assess surfactant biodegradation - impact of sorption on the validity of results. Appl Microbiol Biotechnol 104:1-12

Cserati T, Forgacs E, Oros G (2002) Biological activity and environmental impact of anionic surfactants. Environ Int 28:337-348
Cychosz KA, Thommes M (2018) Progress in the physisorption characterization of nanoporous gas storage materials. Engineering 4:559-566

Deng Y, Zheng X, Bai Y, Wang Q, Zhao J, Huang J (2018) Surfactantcontrolled ink drying enables high-speed deposition of perovskite films for efficient photovoltaic modules. Nat Energy 3:560-566

Dimapilis EAS, Hsu C-S, Mendoza RMO, Lu M-C (2018) Zinc oxide nanoparticles for water disinfection. Sust Envir Res 28:47-56

Ding WH, Fujita Y, Aeschimann R, Reinhard M (1996) Identification of organic residues in tertiary effluents by GC/EI-MS; GC/ CI-MS and GC/TSQ-MS. Fresenius J Anal Chem 354(1):48-55

Fox MA, Dulay MT (1993) Heterogeneous Photocatalysis. Chem Rev 93:341-357

Giahi M, Habibi S, Toutounchi S, Khavei M (2012) Photocatalytic degradation of anionic surfactant using zinc oxide nanoparticles. Russ J Phys Chem 86:689-693

Giger W, Brunner PH, Schaffner C (1984) 4-Nonylphenol in sewage sludge: accumulation of toxic metabolites from nonionic surfactants. Science 225:623-625

Hidaka H, Kubota H, Grätzel M, Pelizzetti E, Serpone N (1986) Photodegradation of surfactants II: Degradation of sodium dodecylbenzenesulphonate catalysed by titanium dioxide particles. J Photochem 30:219-230

Hidaka H, Yamada S, Suenaga S, Kubota H, Serpone N, Pelizzetti E, Grätzel M (1989) Photodegradation of surfactants V: Photocatalytic degradation of surfactants in the presence of semiconductor particles by solar exposure. J Photoch Photobio A 47:103-112

Hidaka H, Zhao J (1992) Photocatalytic degradation of surfactants by $\mathrm{TiO}_{2}$ semiconductor. Colloid Surf 67:165-182

Hidaka H, Zhao J, Kitamura K, Nohara K, Serpone N, Pelizzetti E (1992) Photodegradation of surfactants IX: The photocatalysed oxidation of polyoxyethylene alkyl ether homologues at $\mathrm{TiO}_{2}$-water interfaces. J Photoch Photobio A 67:103-113

Hidaka H, Zhao J, Pelizzetti E, Serpone N (1992) Photodegradation of surfactants. 8. Comparison of photocatalytic processes between anionic sodium dodecylbenzenesulfonate and cationic benzyldodecyldimethylammonium chloride on the $\mathrm{TiO}_{2}$ surface. J Phys Chem 96:2226-2230

Hoffmann AJ, Carraway ER, Hoffmann MR (1994) Photocatalytic production of $\mathrm{H}_{2} \mathrm{O}_{2}$ and organic peroxides on quantum-sized semiconductor colloids. Environ Sci Technol 28:776-785

Hoffmann MR, Martin ST, Choi W, Bahnemann DW (1995) Environmental applications of semiconductor photocatalysis. Chem Rev 95:69-96

Huszla K, Cierniak D, Wysokowski M, Wyrwas B (2018) Non-biological methods for degradation of nonionic surfactants in the aquatic environment. Przem Chem 97:2022-2025

Imbhadon AO, Fitzpatrick P (2013) Heterogeneous photocatalysis: recent advances and applications. Catalysts 3:189-218

Janoska A, Vazquez M, Janssen M, Wijffels RH, Cuaresma M, Vílchez C (2018) Surfactant selection for a liquid foam-bed photobioreactor. Biotechnol Prog 34:711-720

Jardak K, Drogui P, Daghrir R (2016) Surfactants in aquatic and terrestrial environment: occurrence, behavior, and treatment processes. Environ Sci Pollut Res 23:3195-3216

Jia M, Yang Z, Xu H, Song P, Xiong W, Cao J, Zhang Y, Xiang Y, Hu J, Zhou C, Yang Y, Wang W (2020) Integrating N and F co-doped TiO2 nanotubes with ZIF-8 as photoelectrode for 
enhanced photo-electrocatalytic degradation of sulfamethazine. Chem Eng J 388:124388

Kabra K, Chaudhary R, Sawhney RL (2004) Treatment of hazardous organic and inorganic compounds through Aqueous-phase photocatalysis: a review. Indust Eng Chem Res 43:7683-7696

Khunt G (1993) Behavior and fate of surfactants in soil. Environ Toxicol Chem 12:1813-1820

Kim J-H, Kim S-R, Kil H-J, Kim Y-C, Park J-W (2018) Highly conformable, transparent electrodes for epidermal electronics. Nano Lett 18:4531-4540

Kołodziejczak-Radzimska A, Jesionowski T (2014) Zinc Oxidefrom synthesis to application: a review. Materials 7:2833-2881

Komatsu H, Omori K, Kandeel F, Mullen Y (2018) Surfactants improve live cell imaging of human pancreatic islets. Pancreas 47:1093-1100

Könnecker G, Regelmann J, Belanger S, Gamon K, Sedlak R (2011) Environmental properties and aquatic hazard assessment of anionic surfactants: Physico-chemical, environmental fate and ecotoxicity properties. Ecotoxicol Environ Saf $74: 1445-1460$

Krishnakumar T, Jayaprakash R, Pinna N, Singh VN, Mehta BR, Phani AR (2009) Microwave-assisted synthesis and characterization of flower shaped zinc oxide nanostructures. Mat Lett 63:242-245

Lechuga M, Fernandez-Serrano M, Jurado E, Núñez-Olea J, Ríos F (2016) Acute toxicity of anionic and non-ionic surfactants to aquatic organisms. Ecotoxicol Environ Saf 125:1-8

Li X, Du X, Lin H, Li L, Kong X, Zheng C, Tao S, Zhang X (2018) Non-ionic surfactant-novel agents to realize high efficiency nonfullerene opaque and semitransparent organic solar cells with enhanced stability. Org Electron 62:195-202

Liu Y, Kong J, Yuan J, Zhaob W, Zhua X, Suna C, Xiec J (2018) Enhanced photocatalytic activity over flower-like sphere $\mathrm{Ag} /$ $\mathrm{Ag}_{2} \mathrm{CO}_{3} / \mathrm{BiVO}_{4}$ plasmonic heterojunction photocatalyst for tetracycline degradation. Chem Eng J 331:242-254

Liwarska-Bizukojc E, Miksch K, Malachowska-Jutsz A, Kalka J (2005) Acute toxicity and genotoxicity of five selected anionic and nonionic surfactants. Chemosphere 58:1249-1253

Noorimotlagh Z, Kazeminezhad I, Ahmadi M, Ramezani Z (2019) Improved performance of immobilized $\mathrm{TiO}_{2}$ under visible light for the commercial surfactant degradation: role of carbon doped $\mathrm{TiO}_{2}$ and anatase/rutile ratio. Catal Today. https://doi.org/10.1016/j. cattod.2019.08.051

Norman M, Żółtowska-Aksamitowska S, Zgoła-Grześkowiak A, Ehrlich H, Jesionowski T (2018) Iron(III) phthalocyanine supported on a spongin scaffold as an advanced photocatalyst in a highly efficient removal process of halophenols and bisphenol A. J Hazard Mater 347:78-88

Ong CB, Ng LY, Mohamad AW (2018) A review of ZnO nanoparticles as solar photocatalysts: synthesis, mechanisms and applications. Renew Sustain Energy Rev 81:536-551

Özgür Ü, Avrutin V, Morkoç H (2018) Zinc oxide materials and devices grown by molecular beam epitaxy. In: Henini M (ed) Molecular Beam Epitaxy (MBE): From Research to Mass Production. Elsevier, Amsterdam
Pattanaik A, Venugopal R (2019) Role of surfactants in mineral processing: an overview. IntechOpen. https://doi.org/10.5772/intec hopen. 85947

Pelaez M, Nolan NT, Pillai S, Seery MK, Falaras P, Kontos AG, Dunlop PSM, Hamilton JWJ, Byrne JA, O'Shea K, Entezari MH, Dionysiou DD (2012) A review on the visible light active titanium dioxide photocatalysis for environmental applications. Appl Catal B Environ 125:331-349

Pourrahimi AM, Liu D, Andersson RL, Ström V, Gedde UW, Olsson RT (2016) Aqueous synthesis of (210) oxygen-terminated defect-free hierarchical $\mathrm{ZnO}$ particles and their heat treatment for enhanced reactivity. Langmuir 32(42):11002-11013

Rahimpour R, Chaibakhsh N, Zanjanchi MA, Moradi-Shoeili Z (2020) Fabrication of $\mathrm{ZnO} / \mathrm{FeVO}_{4}$ heterojunction nanocomposite with high catalytic activity in photo-Fenton-like process. Journal of Alloys and Compounds 817:152702

Rao NN, Dube S (1995) Photocatalytic degradation of mixed surfactants and some commercial soap /detergent products using suspended $\mathrm{TiO}_{2}$ catalysts. J Mol Cat A 104:L197-L199

Rebello S, Asok AK, Mundayoor S, Jisha MS (2014) Surfactants: toxicity, remediation and green surfactants. Environ Chem Lett $12: 275-287$

Rios F, Fernandez-Arteaga A, Fernandez-Serrano M, Jurado E, Lechuga M (2018) Silica micro- and nanoparticles reduce the toxicity of surfactant solutions. J Hazard Mater 353:436-443

Rosen MJ, Kunjappu JT (2012) Surfactants and interfacial phenomena. John Wiley, New Jessy

Sabouni R, Gomaa H (2019) Photocatalytic degradation of pharmaceutical micro-pollutants using ZnO. Environ Sci Pollut Res 26:5372-5380

Sałata R, Siwińska-Stefańska K, Sokołowska J (2019) Comparative degradation of C. I. Acid Green 25 and C. I. basic blue 9 by electrochemical, photoelectrochemical and photocatalytic oxidation methods. Int J Electrochem Sci 14:792-814

Schneider J, Matsuoka M, Takeuchi M, Zhang J, Horiuchi Y, Anpo M, Bahnemann DW (2014) Understanding $\mathrm{TiO}_{2}$ photocatalysis: mechanisms and materials. Chem Rev 114:9919-9986

Siwińska-Ciesielczyk K, Świgoń D, Rychtowski P, Moszyński D, Zgoła-Grześkowiak A, Jesionowski T (2020) The performance of multicomponent oxide systems based on $\mathrm{TiO}_{2}, \mathrm{ZrO}_{2}$ and $\mathrm{SiO}_{2}$ in the photocatalytic degradation of Rhodamine $\mathrm{B}$ : mechanism and kinetic studies. Coll Surf A: Physicochem Eng Asp. https:// doi.org/10.1016/j.colsurfa.2019.124272

Shet A, Shetty KV (2015) Photocatalytic degradation of phenol using $\mathrm{Ag}$ core- $\mathrm{TiO}_{2}$ shell $\left(\mathrm{Ag} @ \mathrm{TiO}_{2}\right)$ nanoparticles under UV light irradiation. Environ Sci Pollut Res 23:20055

Shukla A, Trivedi SP (2018) Anionic surfactant, linear alkyl benzene sulphonate induced oxidative stress and hepatic impairments in fish Channa punctatus. Proc Zooll Soc 71:382-389

Staples CA, Naylor CG, Williams JB, Gledhhill WE (2001) Ultimate biodegradation of alkylphenolethoxylate surfactants and their biodegradation intermediates. Environ Toxicol Chem 20(11):2450-2455

Tan X, Yim SY, Uppu P, Kleinow KM (2010) Enhanced bioaccumulation of dietary contaminants in catfish with exposure to the waterborne surfactant linear alkylbenzene sulfonate. Aquat Toxicol 99(2):300-308 
Tian C, Zhang Q, Wu A, Jiang M, Liang Z, Jiang B, Fu H (2012) Cost-effective large-scale synthesis of $\mathrm{ZnO}$ photocatalyst with excellent performance for dye photodegradation. Chem Commun 48:2858-2860

Uzma S, Khan S, Murad W, Taimur N, Azizullah A (2018) Phytotoxic effects of two commonly used laundry detergents on germination, growth, and biochemical characteristics of maize Zea mays L seedings. Environ Monit Assess. https://doi.org/10.1007/s1066 1-018-7031-6

van Heerden JL, Swanepoel R (1997) XRD analysis of ZnO thin films prepared by spray pyrolysis. Thin Solid Films 299:72-77

Yang Q, Lin TS, Burton C, Park SH, Ma Y (2016) Physicochemical insights of irradiation-enhanced hydroxyl radical generation from $\mathrm{ZnO}$ nanoparticles. Toxicol Res 5:482-491
Wyrwas B, Dymaczewski Z, Zgoła-Grześkowiak A, Szymański A, Frańska M, Kruszelnicka I, Ginter-Kramarczyk D, Cyplik P, Ławniczak Ł, Chrzanowski Ł (2013) Biodegradation of Triton X-100 and its primary metabolites by a bacterial community isolated from activated sludge. J Environ Manag 128:292-299

Zhang Y, Wan Y (2014) Heterogeneous photocatalytic degradation of Triton X-100 in aqueous TiO2 suspensions. Am J Environ Sci 3:28-35

Zhao J, Hidaka H, Takamura A, Pelizzetti E, Serpone N (1993) Photodegradation of surfactants. 11. Zeta-potential measurements in the photocatalytic oxidation of surfactants in Aqueous $\mathrm{TiO}_{2}$ dispersions. Langmuir 9:1646-1650 